\title{
Effects of neuromuscular electrical stimulation on tibialis anterior muscle of spastic hemiparetic children
}

\author{
Efeitos de estimulação elétrica neuromuscular no músculo tibial anterior em \\ crianças hemiparéticas espásticas
}

Nunes LCBG', Quevedo AAF', Magdalon EC²

\begin{abstract}
Objective: This study evaluated the effects of neuromuscular electrical stimulation (NMES) on muscle strength, range of motion (ROM) and gross motor function, among spastic hemiparetic children while standing, walking, running and jumping. Methods: Ten children were divided into two groups of five. The children who were normally receiving physical therapy sessions twice a week had two 30minute NMES sessions per week (group 1), while those who were having one physical therapy session per week had one 30-minute NMES session per week (group 2), for seven weeks in both groups. The children were evaluated three times: before beginning the NMES protocol (initial), right after the end of the protocol (final) and eight weeks after the final evaluation (follow-up). The evaluations included manual goniometry on ankle dorsiflexion, manual muscle strength of the tibialis anterior and gross motor function (measurements while standing, walking, running and jumping). The statistical analysis was performed using the Wilcoxon and Mann-Whitney tests, considering a p level of 0.05. Results: There were significant increases in muscle strength, gross motor function and passive ROM of ankle dorsiflexion, in both groups, and in active dorsiflexion in the first group. No significant differences were found between the groups. Conclusions: The improvements in ROM, muscle strength and gross motor function demonstrated that the use of NMES was effective in both groups, since no significant differences were found between the groups. This study suggests that NMES may be a useful therapeutic tool, even when applied once a week. Further studies are needed to confirm these findings.
\end{abstract}

Key words: electrical stimulation; hemiparetic children; spasticity; cerebral palsy; tibialis anterior.

\section{Resumo}

Objetivo: Este estudo avaliou os efeitos da estimulação elétrica neuromuscular (EENM) na força, amplitude de movimento (ADM) e função motora grossa (FMG) em pé, andando, correndo e pulando de crianças hemiparéticas espásticas. Métodos: Dez crianças foram divididas em dois grupos de cinco. As que realizavam sessões de fisioterapia duas vezes por semana tiveram duas sessões semanais de EENM de 30 minutos cada (grupo 1), enquanto as que compareciam à uma sessão tiveram uma sessão semanal (grupo 2), ambas por sete semanas. As crianças foram avaliadas três vezes: antes do início do protocolo de EENM (inicial), ao final do protocolo (final) e oito semanas após a avaliação final (tardia). As avaliações englobaram goniometria manual da dorsiflexão de tornozelo, força muscular manual do tibial anterior e função motora grossa, (Gross Motor Function Measure em pé, andando correndo e pulando). A análise estatística foi feita pelos testes de Wilcoxon e Mann-Whitney, com p adotado de 0,05. Resultados: Houve aumentos significativos na força muscular, na FMG e na ADM passiva da dorsiflexão de tornozelo em ambos os grupos, assim como na dorsiflexão ativa no primeiro grupo. Nenhuma diferença significativa foi encontrada entre os grupos. Conclusões: As melhoras obtidas na ADM, força muscular e FMG demonstram que o uso da EENM foi eficaz nos dois grupos, não tendo sido encontradas diferenças significativas entre os mesmos. Este estudo sugere que a EENM pode ser útil no auxílio à terapia, mesmo em baixas freqüências, como uma vez por semana. Estudos adicionais são necessários para confirmar estes achados.

Palavras-chave: estimulação elétrica; crianças hemiparéticas; espasticidade; paralisia cerebral; tibial anterior.

\section{Recebido: 01/08/07 - Revisado: 08/11/07 - Aceito: 08/04/08}

1 Pediatrics Investigation Center, School of Medical Sciences; Department of Biomedical Engineering, School of Electrical and Computer Engineering; Biomedical Engineering Center, Universidade Estadual de Campinas (Unicamp) - Campinas (São Paulo), Brazil

${ }^{2}$ Department of Biomedical Engineering, School of Electrical and Computer Engineering; Biomedical Engineering Center, Unicamp - Campinas (SP), Brazil

Correspondence to: Ligia Christina Borsato Guimarães Nunes, Centro de Investigação em Pediatria, Faculdade de Ciências Médicas; Departamento de Engenharia Biomédica, Faculdade de Engenharia Elétrica e de Computação; Centro de Engenharia Biomédica, Universidade Estadual de Campinas, Rua Padre Vieira, 565, apto. 41, CEP 13015-301, Campinas (SP), Brasil, e-mail: ligiaborsato@hotmail.com 


\section{Introduction $: \because$.}

Cerebral palsy (CP) may be defined as static encephalopathy, and some of its possible consequences are non-progressive movement and posture disturbances ${ }^{1}$. Stroke in children is a consequence of encephalic arterial blockade or rupture that starts abruptly and, within minutes or hours, develops into a neurological syndrome that varies in intensity and consequences $^{2}$. One of the most common impairments due to $\mathrm{CP}$ or stroke is spastic hemiparesis, which is characterized by imbalance between agonist and antagonist muscles that may lead to walking disabilities, muscle contractures and deformities like equinus foot ${ }^{1-3}$. Even among children with mild hemiparesis, equinus foot is a common impairment that affects gait, due to weakness of the tibialis anterior and triceps surae muscles. An ineffective tibialis anterior may decrease foot clearance, which may cause stumbles and falls ${ }^{4}$.

Neurodevelopmental treatment is the most commonly used treatment technique for cerebral palsy. Although this approach acknowledges functional independence as an important treatment goal, the means of obtaining function is based on inhibition of abnormal posture and movement and on improving the child's quality and efficiency of movement by encouraging typical patterns of movement ${ }^{5}$.

Scientific advances have allowed new technologies to be used to help rehabilitation of patients who suffer from neurological problems. Interactions between health sciences and engineering have contributed towards improving quality of life, through promoting functional independence for otherwise dependent patients. Neuromuscular electrical stimulation (NMES) has been shown to be useful in the rehabilitation of neurological patients $^{6-8}$. However, in neuropediatric Physical Therapy (PT) this kind of procedure has not yet been widely explored, since therapists fear increasing spasticity through electrical stimulation. For this reason, NMES is not a common practice for CP patients ${ }^{9,10}$, although it has been used for research on CP subjects, usually with high weekly frequencies of treatment, or up to twice a day by some authors ${ }^{7,11-13}$. These protocols are used mainly for research, and they do not reflect what can be done in large-scale therapy. Although NMES is applied to specific muscles, increases in overall functioning after its use have been documented, because increases in strength and range of movement (ROM) can lead the child to use the limb more effectively ${ }^{12}$. Specific use of NMES on the tibialis anterior muscle can increase ankle ROM and dorsiflexion strength, which may produce more efficient dorsiflexion and clearance during gait.

In most countries, there are huge demands from patients on the healthcare system. The demands are greater than the human and material resources available, thus making it impossible to treat patients daily or even three times a week. Children usually have physical therapy only once or twice a week and it is very difficult to implement a protocol based on what can be found in the scientific literature. Furthermore, in addition to the resource limitations of the system, most families are unable to take their children to and from the physical therapy center more than once or twice a week.

The main aim of the present study was to investigate and compare the effects of NMES on the strength of the tibialis anterior muscle and on active and passive range of motion (ROM) of ankle joint dorsiflexion, and in relation to the more sophisticated aspects of gross motor function (GMF), between children undergoing NMES once and twice a week.

\section{Materials and methods $: \therefore$.}

The research protocol was approved by the institutional ethics committee of the School of Medical Sciences, Universidade Estadual de Campinas (Unicamp), Brazil, under the procedure number 468/2002. A written informed consent form giving agreement to participation and publication of results was signed by the children's parents. All children at the neuropediatric physical therapy outpatient clinic of Unicamp's teaching hospital who met the selection criteria and whose parents agreed to their participation were recruited as a convenience sample. The selection criteria were that the patients should be users of conventional physical therapy (mainly based on Bobath's neurodevelopmental approach), have spastic hemiparesis (due to CP or stroke), be aged between seven and 15 years, be able to walk independently, have no cognitive impairments, be collaborative, have surface sensitivity preserved in their legs, have no ankle deformities, have had no botulinum toxin application for at least six months before the study and have had no previous triceps surae tendon surgery.

Ten children aged seven to fifteen years were chosen: eight with $\mathrm{CP}$ and two with stroke. They were divided into two groups of five (with one children with stroke in each group), according to their usual previous therapy frequencies. Thus, children who were having physical therapy twice a week were placed in group 1 and children who were having physical therapy once a week were placed in group 2. Descriptive data from these children were: age range 7 to 14.8 years (mean 11.34 years); seven males and three females; five affected on the left side and five affected on the right side.

The patients underwent NMES sessions for seven weeks, twice a week in group 1 (total of 14 sessions) and once a week in group 2 (total of seven sessions). Each session had a length of 30 minutes. All the children completed the protocol.

The NMES equipment complied with the International Electrotechnical Commission (IEC) standards 601 and 6012-10, which lay down safety rules for electromedical devices and 
electrical stimulators, respectively. It is important to emphasize that all the children continued to attend their conventional physical therapy sessions at the neuropediatric physical therapy outpatient clinic of Unicamp's teaching hospital.

The study was single-blinded and there were three NMES evaluations: firstly, one week before beginning the protocol (initial); secondly, right after the end of the protocol (final); and thirdly, eight weeks after the final evaluation (follow-up). The examiner was blind to the group in which each child was placed. The evaluation tests consisted of passive and active manual ankle dorsiflexion goniometry, measured in degrees using a handheld goniometer, and the Research Medical Council manual muscle strength test for the tibialis anterior and plantar flexors ${ }^{14}$. Goniometry was performed with the subject in supine position with extended knees, and the measurement was made at the neutral position between dorsal flexion and plantar flexion, id est, $0^{\circ}$ of dorsal flexion. These tests were chosen because of their easy applicability, low cost and wide application in clinical practice. Another test was gross motor function (GMF) measurement, which evaluates capabilities in some functional activities performed by children. In the present study, only the GMF dimensions of standing, walking and climbing were used, which were the dimensions that were expected to change after applying the NMES protocol ${ }^{15}$.

The NMES sessions (30 minutes each) took place at Unicamp's Center of Investigations in Pedriatrics (CIPED). During these sessions, the children were seated on a comfortable chair, with knees positioned at $90^{\circ}$ of flexion. They were barefoot, with their heels placed in contact with floor (Figure 1). For patients whose heels did not reach the ground, a small support box was placed under their feet. NMES electrodes were placed on the skin surface of the paretic side, over the tibialis anterior muscle and near its motor point. The parameters used were: pulse frequency of $50 \mathrm{~Hz}$, pulse width of $250 \mu$ s and on/off ratio of five seconds stimulation and ten seconds rest. These parameters were chosen based on electrical stimulation studies in the literature ${ }^{16-20}$ and on pilot tests performed on seven normal adults (because of the lack of children to act as volunteers). These parameters were shown to evoke a muscle response with minimal discomfort to the patients. NMES was expected to induce a visible muscle contraction, without pain. The current intensity applied was chosen during the sessions, according to the patient's sensitivity. The maximum intensity reached during therapy ranged from 28 to $44 \mathrm{~mA}$.

The Wilcoxon nonparametric test was used to compare different dependent variables within a group, and the MannWhitney test was applied for comparisons between groups. A $\alpha$ of 0.05 was chosen as the level of statistical significance. Nonparametric tests are more suitable than parametric tests for analyzing small sample sizes and in evaluations that attribute scores instead of absolute values ${ }^{21}$.

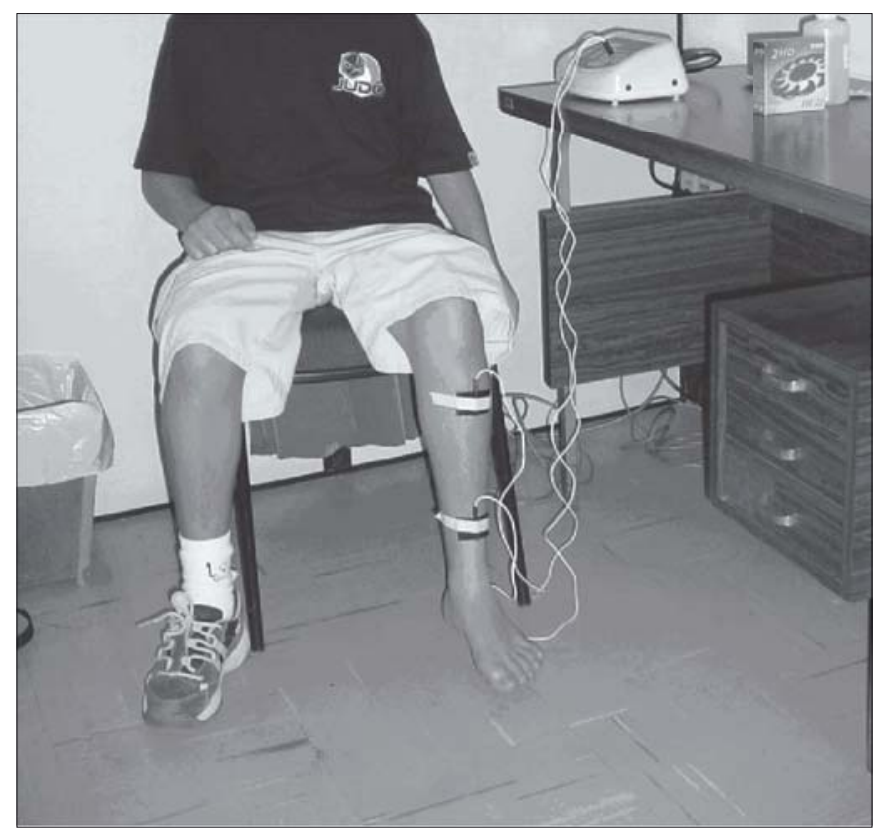

Figure 1. Subject positioning during neuromuscular electrical stimulation (NMES) protocol.

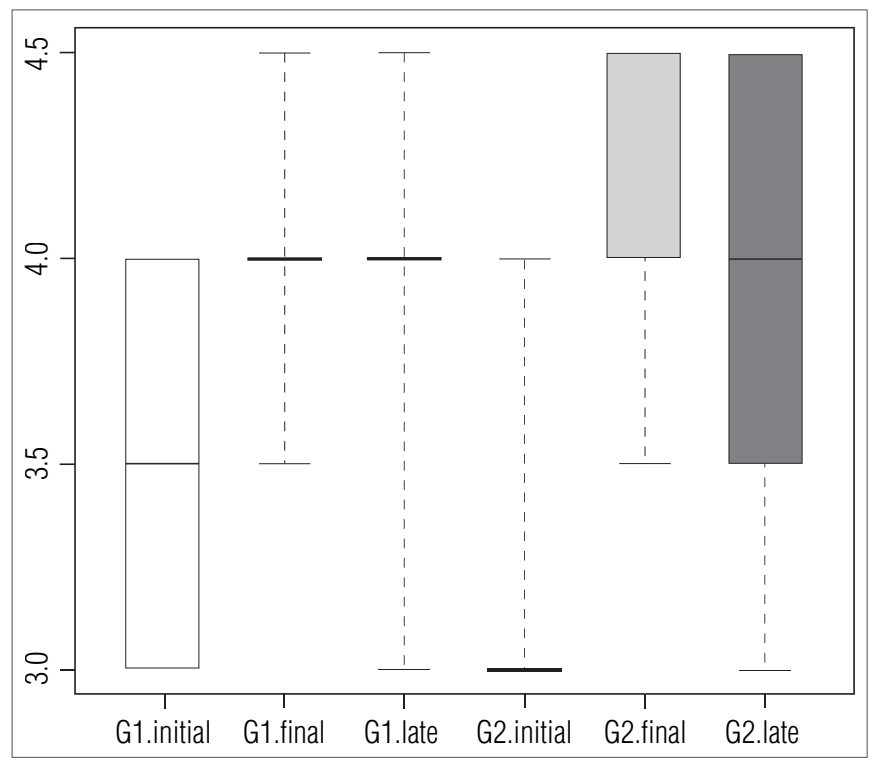

Figure 2. Median, minimum and maximum strength scores and 25 and 75 percentiles (edges of the boxes) from initial, final and follow-up evaluations of group one (G1) and group two (G2).

\section{Results : : .}

\section{Strength}

For anterior tibialis muscle strength (paretic side), the median scores and the 25 and 75 percentiles for the initial, final and follow-up evaluations are shown in Figure 2. There was a significant difference between the initial and final evaluations of the strength test for paretic side ankle dorsiflexion $(p=0.05)$ in group 1. Differences were also found in strength tests for paretic side ankle dorsiflexion between the initial and final 
scores $(\mathrm{p}<0.05)$ and between the initial and follow-up evaluations for group 2. No significant differences were found between the initial and follow-up evaluations for group 1 . However, the group 1 follow-up evaluation values were found to be intermediate between the initial and final values. Comparison using the Mann-Whitney test did not show any significant difference between groups 1 and 2 .

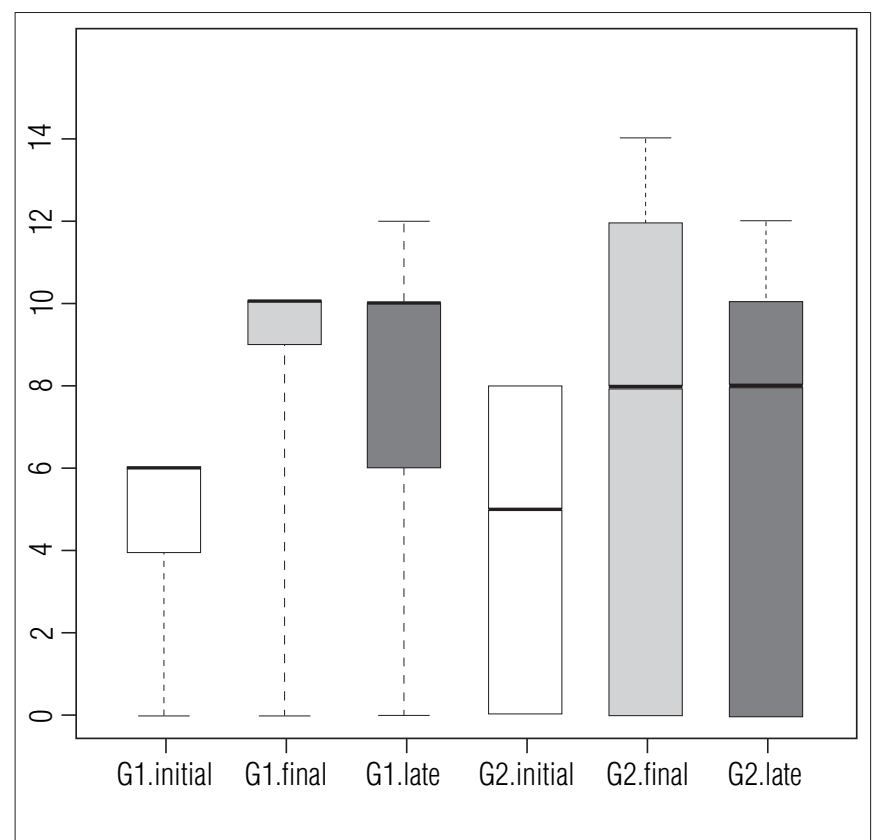

Figure 3. Active range of motion boxplot with median, minimum and maximum scores and 25 and 75 percentiles (edges of the boxes) from initial, final and follow-up evaluations of group one (G1) and group two (G2).

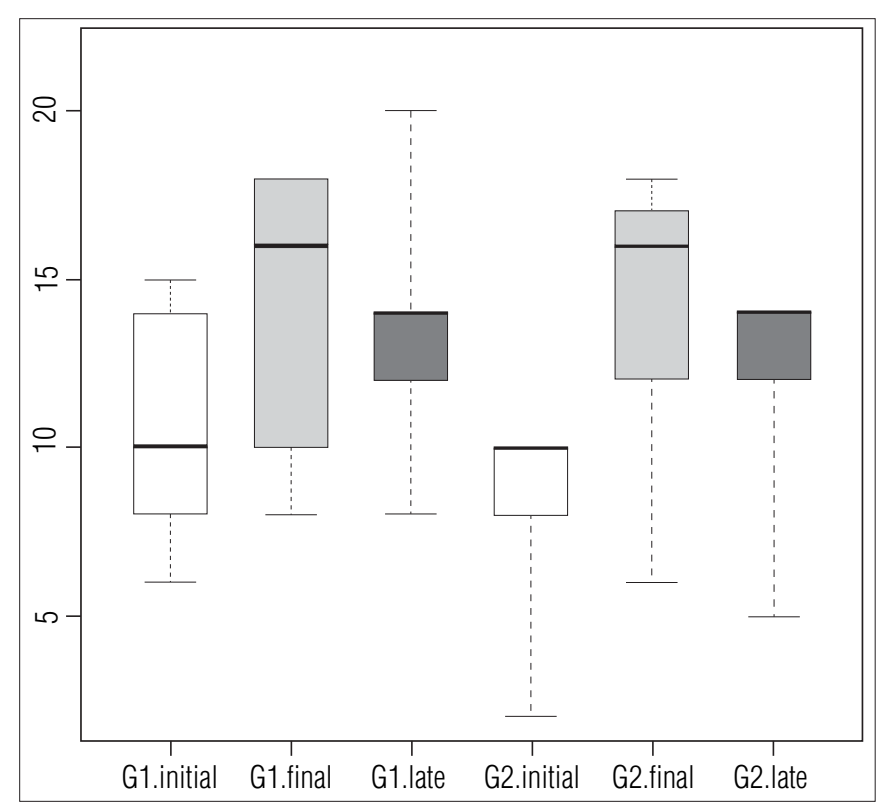

Figure 4. Passive range of motion boxplot with median, minimum and maximum scores and 25 and 75 percentiles (edges of the boxes) from initial, final and follow-up evaluations of group one (G1) and group two (G2).

\section{ROM measures}

The goniometric results shown here are from the affected side. Figures 3 and 4 show the medians and percentiles obtained from active and passive ankle dorsal flexion ROM. Statistical analysis found significant changes $(p=0.05)$ between initial and final and between initial and follow-up for both active and passive dorsal flexion in group 1, and between initial and final and between initial and follow-up for passive dorsal flexion $(\mathrm{p}<0.05)$ in group 2. Comparison using the Mann-Whitney test did not show any significant difference between groups 1 and 2 .

\section{Gross motor function (GMF) measurement}

This measurement scale attempts to quantify function and functional changes over time and is divided into five dimensions: lying and rolling; sitting; kneeling and crawling; standing; and walking, running and jumping ${ }^{15}$. If the dimensions of standing and walking, running and jumping are combined, the maximum score that can be achieved is 105 . The medians obtained by groups 1 and 2 are shown in Figure 5. Group 1 reached 94.28\% of the total score possible in the initial evaluation and $97.14 \%$ in the final and follow-up assessments. Group 2 reached a mean of 95.23\% of the total score possible in the initial evaluation, $98.09 \%$ in the final assessment and $97.14 \%$ in the follow-up assessment.

The Wilcoxon test showed that there were significant differences between the initial and final evaluations for groups 1 and $2(\mathrm{p}<0.05)$, and between the initial and follow-up evaluations $(p=0.05)$ for group 1. All final and

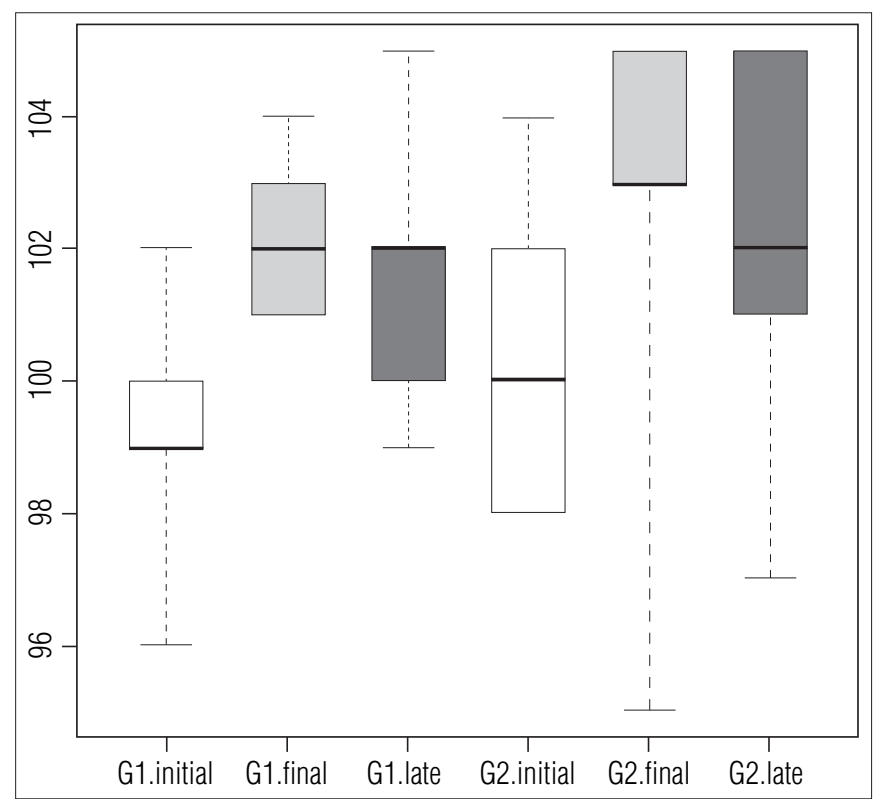

Figure 5. Gross motor function (GMF) measurement boxplot with median, minimum and maximum scores and 25 and 75 percentiles (edges of the boxes) from initial, final and follow-up evaluations of group one (G1) and group two (G2). 
follow-up results were higher than the initial scores. The Mann-Whitney test did not show any differences between groups 1 and 2 .

\section{Discussion $: \therefore$.}

In the scientific literature, some studies on NMES for hemiparetic spastic children have shown that it is possible to increase muscle strength and range of motion, and to promote functional improvements in motor tasks among $\mathrm{CP}$ children ${ }^{10,12}$. Although NMES is a therapeutic resource directed specifically to one muscle or muscle group, its results can be reflected in overall improvements in function, because children can reach better results in their overall functioning through improved strength and range of movement. However, the studies that have shown this result used high-frequency therapies.

In our study, NMES was applied only once or twice a week. Increases in tibialis anterior muscle strength were observed in both groups, with no difference between groups. In addition, the values reached in the follow-up evaluation were higher than the initial values. This suggests that, with the aid of NMES, even with weekly sessions, satisfactory progress can be obtained in relation to hemiparetic spastic muscle strength. In a review of the literature conducted by Kerr, McDowell and McDonough ${ }^{17}$, the quality of the electrical stimulation protocols was analyzed, as well as the results obtained, and it was noticed that there was a significant increase in anterior tibialis muscle strength. Therefore, our findings confirm what is shown in the literature.

Furthermore, neuronal plasticity mediated by NMES is still a subject of research. Some authors have suggested theories about plasticity mechanisms, and have observed that children have better recovery capacity than adults ${ }^{22-26}$. Neuronal plasticity was not directly evaluated here, but the changes in GMF indicate that it may have occurred, because function was improved after NMES.

Hazlewood et al. ${ }^{27}$ found increased tibialis anterior muscle strength after 35 days of treatment with NMES, for one hour per day. Other muscle groups have also been found to strengthen as a result of NMES protocols, for example the intrinsic hand muscles $^{28}$ and the gluteus maximus ${ }^{29}$. According to Damiano, Dodd and Taylor 9 , intense electrical stimulation is one way to increase muscle strength in CP cases.

Regarding GMF, there were increases in the scores between the initial and final evaluations in both groups, and between the initial and follow-up evaluations in group 1. These increases seem to indicate that the children's functional performance was better after NMES than before it. In group
1 (two sessions a week), this increase was also present eight weeks after the end of the sessions. However, the comparisons between groups 1 and 2 did not show any statistically significant differences in any of the evaluations. Some studies have also shown functional increases in GMF due to electrical stimulation ${ }^{12,17,30}$. Bertoti et $\mathrm{al}^{30}$ found that GMF improved after electrical stimulation protocol during gait in some muscles, including the tibialis anterior. They used percutaneous intramuscular electrical stimulation in diplegic children. Kerr et $\mathrm{al}^{31}$ found no statistically significant differences in GMF between evaluations before and after a 16-week NMES protocol, in which NMES was applied to a group of $18 \mathrm{CP}$ children for one hour per day, five days per week.

Finally, with regard to range of movement (ROM) measurements, it was observed that there was an increase in active dorsiflexion ROM in group 1, but group 2 did not show this result in active ROM. This can be explained by the way that the measurements were made: from the neutral position between dorsiflexion and plantar flexion. This method may have masked possible ROM increases in patients who did not reach the neutral position actively. Another possible reason was the high percentiles observed in group 2, thus showing large variability in ROM in this group. In passive dorsiflexion ROM, both groups had improvement between the initial and final evaluations and between the initial and follow-up evaluations. There were no differences between groups 1 and 2 in any of the evaluations. Some studies seem to confirm our findings with regard to improvements in passive ROM after electrical stimulation therapies ${ }^{17,30}$.

This study presented limitations due to the small sample size, and therefore it is not conclusive. Nevertheless, it was the first study to consider the influence of therapy frequency and it focused on low weekly frequencies, which are closer to reality.

\section{Conclusions : : :}

Neuromuscular electrical stimulation on the anterior tibialis muscle was an effective coadjuvant for the rehabilitation of hemiparetic spastic children in this study, thereby increasing their strength, range of motion and standing, walking, running and jumping function. In our study, weekly therapy frequencies still enabled positive results. The children exposed to one weekly NMES session had almost the same results as those who had NMES twice a week, and the groups were not statistically different regarding the data obtained in all evaluations. The results thus justify the use of NMES protocols once a week, which is feasible within the realities of physical therapy practice, given all the public healthcare problems described earlier. It is important to emphasize that 
in order to benefit from NMES therapy, children must comply with the instructions given (to stay seated or in a certain position) and help in controlling the current intensity. Therefore, their skin sensitivity must be preserved, and they should also not present any significant cognitive impairment. Further studies, with larger sample sizes, need to be conducted to confirm the current results and to support the use of NMES at low frequencies of therapy.

\section{Referências bibliográficas :}

1. Nelson WE. Tratado de Pediatria. 14ª ed. (Translated by Marcio Moacir de Vasconcelos). Rio de Janeiro: Guanabara Koogan; 1997.

2. Rowland LP. Merrit: Tratado de Neurologia. $7^{\mathrm{a}}$ ed. Rio de Janeiro: Guanabara Koogan; 1986.

3. Perry J. Determinants of muscle function in the spastic lower extremity. Clin Orthop Relat Res. 1993;288:10-25.

4. Orlin MN, Pierce SR, Stackhouse CL, Smith BT, Johnston T, Shewokis PA et al. Immediate effect of percutaneous intramuscular stimulation during gait in children with cerebral palsy: a feasibility study. Dev Med Child Neurol. 2005;47(10):684-90.

5. Law M, Darrah J, Pollock N, Rosenbaum P, Russell D, Walter SD et al. Focus on function - a randomized controlled trial comparing two rehabilitation interventions for young children with cerebral palsy. BMC Pediatr. 2007;7:31.

6. Bower E, Michell D, Burnett M, Campbell MJ, McLellan DL. Randomized controlled trial of physiotherapy in 56 children with cerebral palsy followed for 18 months. Dev Med Child Neurol. 2001;43(1):4-15.

7. Chae J, Fang ZP, Walker M, Pourmehdi S, Knutson J. Intramuscular electromyographically controlled neuromuscular electrical stimulation for ankle dorsiflexion recovery in chronic hemiplegia. Am J Phys Med Rehabil. 2001;80(11):842-7.

8. Giuffrida JP, Crago PE. Reciprocal EMG control of elbow extension by FES. IEEE Trans Neural Syst Rehabil Eng. 2001;9(4):338-45.

9. Damiano DL, Dodd K, Taylor NF. Should we be testing and training muscle strength in cerebral palsy? Dev Med Child Neurol. 2002;44(1):68-72.

10. Wiley ME, Damiano DL. Lower-extremity strength profiles in spastic cerebral palsy. Dev Med Child Neurol. 1998;40(2):100-7.

11. Scheker LR, Chesher SP, Ramirez S. Neuromuscular electrical stimulation and dynamic bracing as a treatment for upper-extremity spasticity in children with cerebral palsy. J Hand Surg [Br]. 1999;24(2):226-32.

12. Wright PA, Granat MH. Therapeutic effects of functional electrical stimulation of the upper limb of eight children with cerebral palsy. Dev Med Child Neurol. 2002;42(11):724-7.

13. Sommerfelt K, Markestad T, Berg K, Saetesdal I. Therapeutic electrical stimulation in cerebral palsy: a randomized, controlled, crossover trial. Dev Med Child Neurol. 2001;43(9):609-13.

14. Kendall FP, McCreary EK, Provance PG. Músculos: Provas e Funções. $4^{a}$ ed. São Paulo: Manole; 1995. p. 4-5.

\section{Acknowledgements : :}

The authors would like to thank Coordination for the Improvement of High Education Personnel (CAPES), for financial support, Quark Medical Devices for providing the Functional Electrical Stimulation (FES) equipment; Center of Investigations in Pedriatrics (CIPED) for providing a place to perform NMES and the evaluations, and especially the volunteers and their parents.

15. Russell DJ, Rosenbaum PL, Cadman DT, Gowland C, Hardy S, Jarvis S. The gross motor function measure: a means to evaluate the effects of physical therapy. Dev Med Child Neurol. 1989;31(3):341-52.

16. Scott 0 . Efeitos estimulantes. In: Kitchen S, Bazin, S, editores. Eletroterapia de Clayton. 10ª ed. São Paulo: Manole; 1998. p. 111-9.

17. Kerr C, McDowell B, McDonough S. Electrical stimulation in cerebral palsy: a review of effects on strength and motor function. Dev Med Child Neurol. 2004;46(3):205-13.

18. Scott OM, Vrbová G, Hyde SA, Dubowitz V. Effects of chronic low frequency electrical stimulation on normal human tibialis anterior muscle. J Neurol Neurosurg Psychiatry. 1985;48(8):774-81.

19. Guirro ECO, Guirro RRJ. Fisioterapia em Estética: fundamentos, recursos e patologias. $2^{a}$ ed. São Paulo: Manole; 1996. p.91-117.

20. Mylon Tech Health Technologies Inc (homepage on internet). Ottawa: What is N.M.E.S.? (cited 2008 Apr 15). Available from: http://www.mylontech. com/faq2.asp

21. IATROS - Estatística em ciências da saúde (homepage on internet). Recife: Escolha de testes estatísticos (cited 2004 Apr 20). Available from: http:// www.vademecum.com.br/iatros/Testes.htm

22. Daly JJ, Marsolais EB, Mendell LM, Rymer WZ, Stefanovska A, Wolpaw JR et al. Therapeutic neural effects of electrical stimulation. IEEE Trans Rehabil Eng. 1996;4(4):218-30.

23. Kroon JR, ljzerman MJ, Lankhorst GJ, Zivold G. Electrical stimulation of the upper extremity in stroke: comparison of two stimulation strategies [monograph on internet]. Roessing Research and Development [Accessed on 2004 Mar 10]. Available from: http://www.rrd.nl/www/publications/ Esetueis.pdf.

24. Piovesana AMSG. Paralisia cerebral hemiparética: aspectos evolutivos, plasticidade cerebral, e especialização hemisférica (tese de Doutorado). Campinas (SP): Unicamp; 1999.

25. Villar FAS. Alterações Centrais e Periféricas Após Lesão do Sistema Nervoso Central. Considerações e Implicações para a Fisioterapia. Braz J Phys Ther. 1997;2(1):19-34.

26. Rushton DN. Functional electrical stimulation and rehabilitation - an hypothesis. Med Eng Phys. 2003;25(1):75-8.

27. Hazlewood ME, Brown JK, Rowe PJ, Salter PM. The use of therapeutic electrical stimulation in the treatment of hemiplegic cerebral palsy. Dev Med Child Neurol. 1994;36(8):661-73. 
28. Carmick J. Use of neuromuscular electrical stimulation and dorsal wrist splint to improve the hand function of a child with spastic hemiparesis. Phys Ther. 1997;77(6):661-71.

29. van der Linden ML, Hazlewood ME, Aitchison AM, Hillman SJ, Robb JE. Electrical stimulation of gluteus maximus in children with cerebral palsy: effects on gait characteristics and muscle strength. Dev Med Child Neurol. 2003;45(6):385-90.
30. Bertoti DB, Stanger M, Akers JM, Betz RR. Investigation of the efficacy of percutaneous intramuscular electrical stimulation for children with cerebral palsy, spastic diplegia. Gait \& Posture. 1996;4:191-2.

31. Kerr C, McDowell B, Cosgrove A, Walsh D, Bradbury I, McDonough S. Electrical stimulation in cerebral palsy: a randomized controlled trial. Dev Med Child Neurol. 2006;48(11):870-6. 